EPJ Web of Conferences 45, 01050 (2013)

DOI: $10.1051 /$ epjconf/20134501050

(C) Owned by the authors, published by EDP Sciences, 2013

\title{
Disintegration of materials by cavitating microjets
}

\author{
B. Knížat ${ }^{1}$, M. Mlkvik ${ }^{1}$, R. Olšiak ${ }^{1}$ \\ ${ }^{1}$ Strojnícka fakulta STU v Bratislave, Nám. slobody 17, 81231 Bratislava, Slovensko
}

\begin{abstract}
In the paper is presented an investigation of material disintegration by cavitating microjets. Cavitating microjet develops behind the micro-orifice at high flow speeds, when local pressure drop initiates a cavitation phenomenon. Described is a method and presented are selected results of experiments. Experiments were carried out with 2 micro-orifices at different flow conditions (cavitation number, distance between sample and micro-orifice). Experiments are based on flow visualisation as well as on a character of material displacement.
\end{abstract}

\section{Introduction}

Effects of cavitating flow are mostly presented negatively - as one of the reasons of a destruction of hydraulic devices. But there are some applications, when the phenomenon is utilized - for example for a surface peening, or for a disintegration of materials - it depends on the intensity of cavitation and on the time of action.

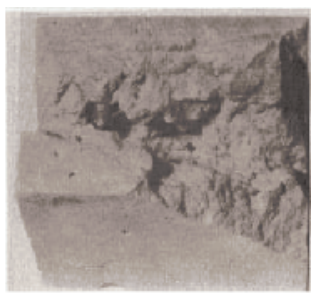

Fig. 1. Sample of dolomite exposed to cavitation [2].

In the figure 1 is pictured the action of cavitation taken from the paper [2]. It shows a disintegration of a stone (dolomite) by a moving cavitating jet.

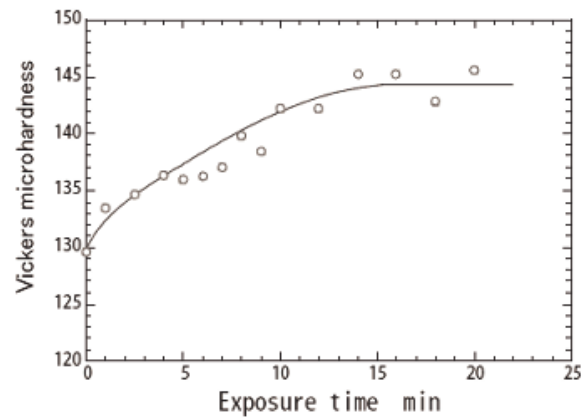

Fig. 2. Measured course of hardness as a function of the exposure time to cavitation [3].
From the paper [2] follows that a cavitating jet with suitable parameters has a considerable disintegration action on hard materials.

Of course, the resulting effect of cavitating jet depends on mechanical properties of the material.

In the figure 2 is a course of metal surface hardness in dependence on the time of exposure to the cavitating jet.

It may be seen, that the hardness at the beginning grows. No material erosion occurs in the first phase of the cavitating jet exposure and the cavitation may be utilized for increasing of the surface hardness (peening) without surface damage. On the contrary, for materials as for example rock is erosion considerable during the whole period of a cavitating jet exposure.

The cavitation is not utilized for metals cutting due to their strain hardening. But the cavitation may be used for non-chemical metal surfaces etching. This method of a surface modification is more suitable than an application of aggressive acids. The aim of our research is to acquire knowledge about cavitation damage of materials where the strain hardening does not occur.

\section{Experiment methodology}

Experiments were carried out on the device generating high-speed cavitating flows with velocities up to $150 \mathrm{~m} / \mathrm{s}$. Such a device at "standard" dimensions would require very high input power. So the base part of the experimental device was a micro-orifice where necessary hydraulic input power does not exceed order of kilowatts. Beside this it was very simple to explore the structure of a cavitating jet by using a high-speed camera. In the figure 3 is a scheme of the whole experimental system. Some other detailed information is possible to find in [1]. 


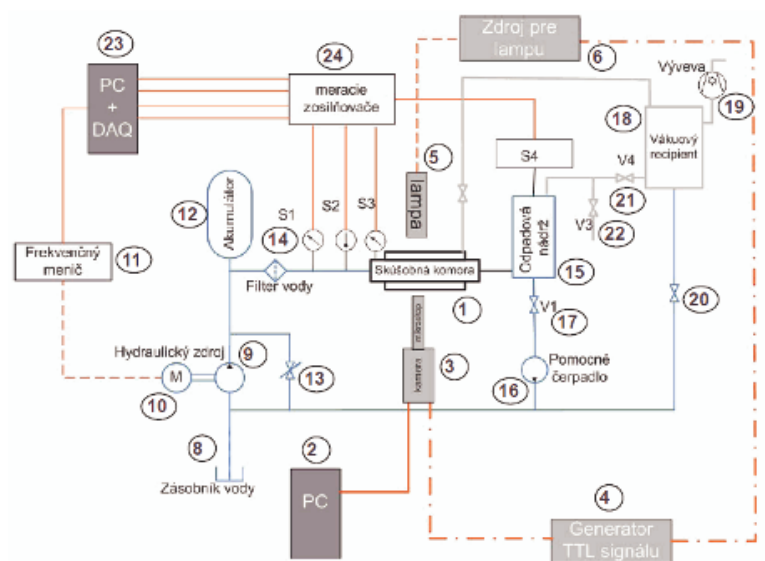

Fig. 3.Experimentaldevice. Detailed description in [1].

A fundamental part of the experimental device is a hydraulic circuit making the circulation of water through the micro-orifice possible. The position (1) in the figure 3 denotes the so called Lichtarowicz cell where the orifice is placed. The position (5) is the lamp Nanolite with the source Strobokin and the position (3) is the high-speed camera Redlake Y3. The duration of lamp flashesis $18 \mathrm{~ns}$ andthe maximumflashes frequency is $20 \mathrm{kHz}$. In the circuit is a piston pump (9) with maximum pressure 15 MPa.

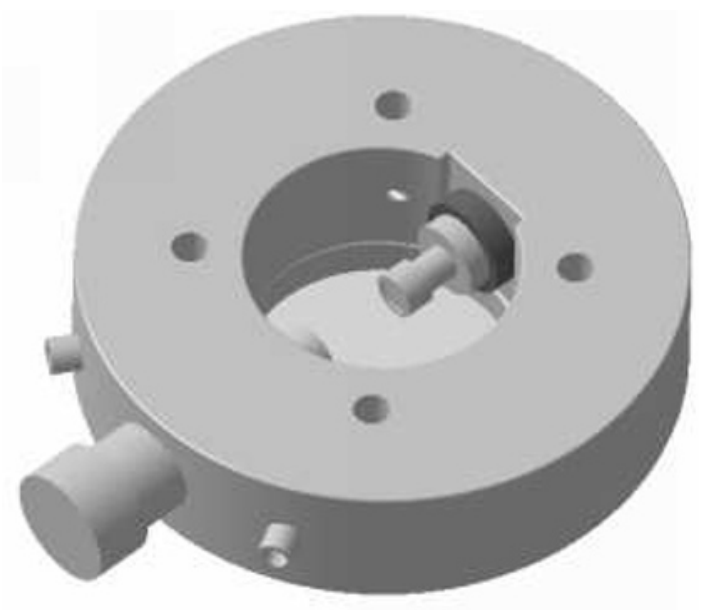

Fig. 4. Lichtarowicz cell.

In the figure 4 is pictured the Lichtarowicz cell. It is transparent from both sides. The orifice and the sample holder are placed inside the cell. The transparent walls make the observation of the sample impinged by a high speed cavitating jet possible. The water is drainaged from the cell to the atmospheric reservoir.

\subsection{Orifices}

In the experiments were used more types of orifices:

- brass orifices

- $\quad$ hard alloy orifices

- $\quad$ sapphire glass orifices



Fig. 5. Orifices made from a hard alloy

In the figure 5 are the orifices with diameters 0,580 $\mathrm{mm}$ and $0,350 \mathrm{~mm}$ made from hard alloy. The main part of the experiments was carried out with hard alloy orifices due to their damage resistance.

The sapphire glass orifices were relatively fragile and the manipulation with them must be very careful.

\subsection{Sample and its position}

Observation and evaluation of the cavitation damage was carried out on lead samples. The mean advantage was the fact, that lead cannot be hardened by stress and the erosion is taking place from the beginning of the experiment. The time of the experiment may be shortened.



Fig. 6. Position of the orifice and sample.

In the figure 6 is a sample position respect to the orifice. The diameter of the sample placed in the holder is D. The distance between the sample and the orifice is L. The distance $\mathrm{L}$ is adjustable. Constant flow rate and pressure conditions during the experiment were kept. It was achieved by measurement software with integrated PID controller. In order to attain constant water parameters its temperature was kept on a given value by cooling.

\subsection{Parameters of flow}

Cavitating flow is defined by the cavitation number:

$$
\sigma=\frac{p_{2}-p_{v}}{\frac{v_{2}^{2}}{2} \rho}
$$

where $\mathrm{p}_{2}$ - downstream pressure, $\mathrm{p}_{\mathrm{v}}$ - vapour pressure, $\mathrm{v}_{2}$ - downstream velocity, $\rho$ - density. 
The flow through the orifice describes also the Bernoullli equation:

$$
\frac{p_{1}-p_{2}}{\rho}=C_{v}^{2} \frac{v_{2}^{2}}{2}
$$

After some rearrangement of equations (1) and (2) we easily obtain:

$$
\frac{1}{\sigma}=\frac{1}{C_{v}^{2}} \frac{p_{1}-p_{2}}{p_{2}-p_{v}}
$$

The parameter $\frac{p_{1}-p_{2}}{p_{2}-p_{v}}$ is only another form of a cavitation number. The relation between $\sigma^{-1}$ and $\frac{p_{1}-p_{2}}{p_{2}-p_{v}}$ is linear if $\mathrm{C}_{\mathrm{v}}$ is constant. Experiments confirmed this assumption.

\section{Results of the experiment}

Experiment may be divided into two parts. The first one was a visualization of the cavitating jet by using a highspeed camera. In the second one the erosion effects were observed.

\subsection{Visualization of a cavitating jet}

The structure of a cavitating cloud behind the microorifice was investigated by the visualisation. In the figure 3 are three different cases of cavitating flow characterized by the cavitation number value.

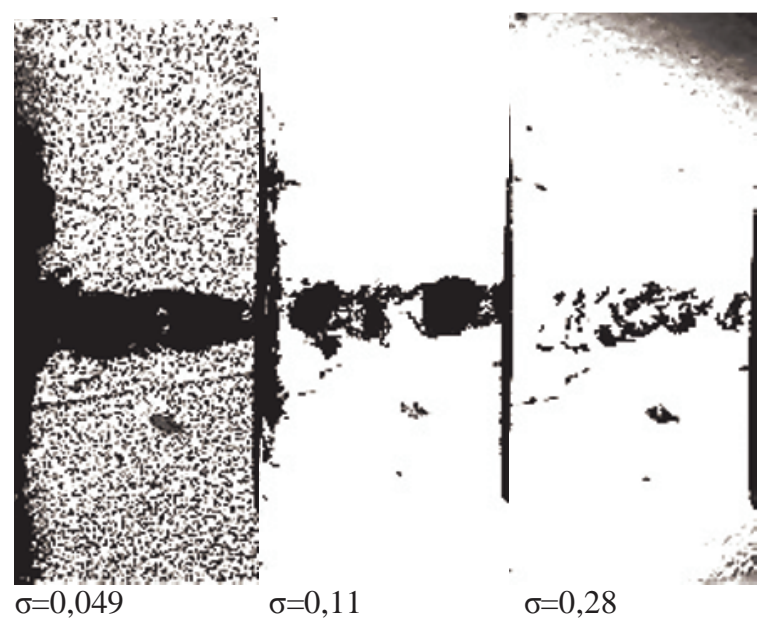

Fig. 7. The form of a cavitating jet (flow from right to left).

As it is clear from the figure, the intensity of cavitation grows if cavitation number drops. First cavitation bubbles may be observed at values of $\sigma=0,350$. The path the bubbles travel during their lifetime depends also on the stream flow and on the dynamics of the bubbles. Interesting is also a change of the structure of the stream. At high cavitation numbers a system of solitary bubbles may be observed. These bubbles are destroyed on a confined area on the sample. The bubbles create packets or clusters if $\sigma$ is decreased (the value $\sigma=0,11$ in the figure 7). These packets are impinging the sample surface. Continuous cavitating flow develops from the periodical packet structure if the $\sigma$ is further decreased. If the $\sigma$ drops, the area of a diameter D (figure 6) grows. Diameter D defines the area where the bubbles vanish.

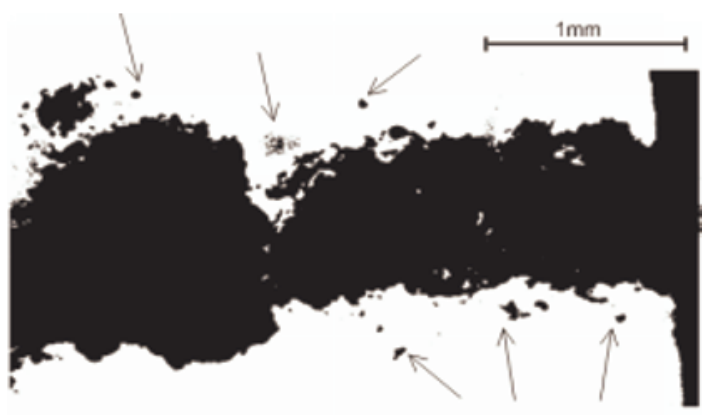

Fig. 8. Detail of a cavitating jet (flow from right to left).

In the figure 8 is a structure of a cavitating jet at very low values of $\sigma$ (less than 0,07). The arrows denote the regions of vapour separated from the main stream. The structure of a cavitating jet has the fundamental influence on the character of the sample erosion.

\subsection{Erosive effects}

Owing to a shortening the time of experiment we used a lead sampleduring the investigation of the erosive effects. We can say, that a dual character of damage was observed.
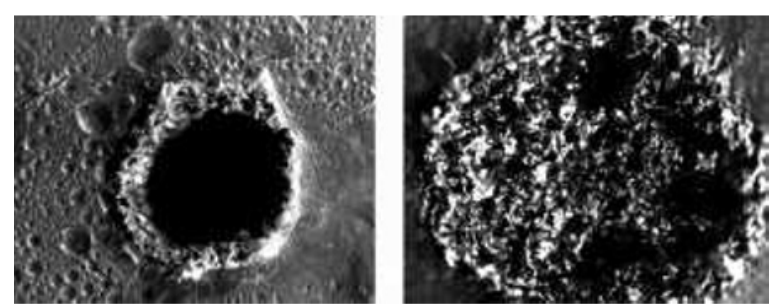

Fig. 9. Sample damage: Type A (left) and B (right).

In the figure 9 left is the damage of type A and right is the damage of type $\mathrm{B}$. The character of the damage depends on the position of the sample respect to the orifice. The damage of type $\mathrm{A}$ is typical for short distances and damage of type B is typical for greater distances between the sample and the orifice. This knowledge is also in accordance with other sources [2].

\subsection{Analysis of cavitation damage}

The character of cavitation damage depends on the position where the cavitating stream collapses. This position is dependent on the time of bubble collapse - so called Rayleigh time [1]:

$$
\tau=0.915 \cdot R_{0} \cdot \sqrt{\frac{\rho}{p_{\infty}-p_{v}}}
$$


where $\mathrm{R}_{0}$ - initial bubble radius, $\mathrm{p}_{\infty}$ - pressure of the surroundings, $\mathrm{p}_{\mathrm{v}}$ - vapour pressure.

Whether the majority of bubbles collapse in the centre of the sample or further from the centre at the diameter D (figure 6), depends on the time $\tau$.

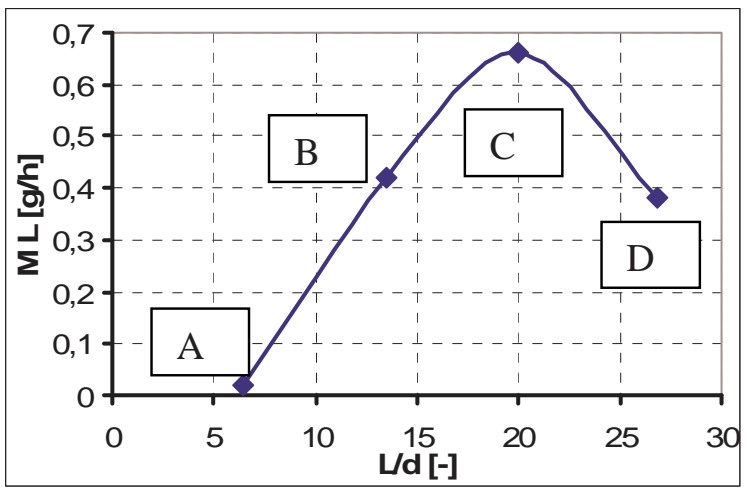

Fig. 10. Mass loss in dependence on $\mathrm{L} / \mathrm{d}$.

The course of mass loss in dependence on the distance $\mathrm{L} / \mathrm{d}$ is in the figure 10 . There are 4 points $(\mathrm{A}, \mathrm{B}, \mathrm{C}, \mathrm{D})$ in the figure, each of them denotes measured value for a corresponding distance. The maximum mass loss is in the point $\mathrm{C}$. In the figure 11 are images of damage for all points $(\mathrm{A}, \mathrm{B}, \mathrm{C}, \mathrm{D})$.



A B

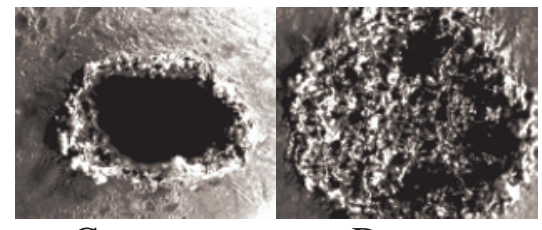

C

$\mathrm{D}$

Fig. 11. Surface damage in dependence on parameter $\mathrm{L} / \mathrm{d}$.

It is surprising that maximum damage does not occur in point A (minimum distance between the orifice and sample).

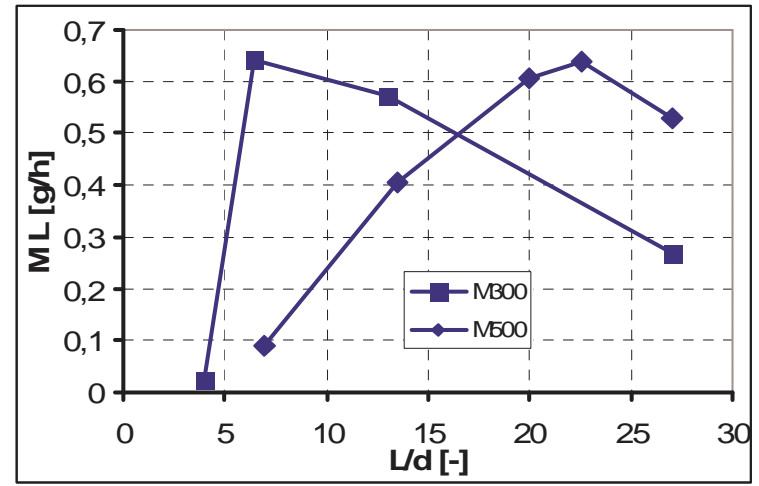

Fig. 12. Measured mass losses for 2 orifices and hydraulic power $180 \mathrm{~W}$.
It corresponds with the hypothesis, that the position of a bubble collapse is crucial and is connected with the jet velocity and Rayleigh time. The material is even almost untouched in the centre of the sample where the jet impinges the surface (point $\mathrm{A}$ in the figure 10 and figure 11). The reason is that a cavitating cloud is drifted in a radial direction and the bubble collapse occurs far from the centre (figure 6). The damage in the point D is caused only by the greatest collapsing bubbles. The number of them is small and they are impinging the sample in a greater area.

In the figure 12 is a course of the damage in dependence on a dimensionless distance $\mathrm{L} / \mathrm{d}$ for the same hydraulic power $Q \Delta p$. Pictured are the results for orifices M300 (diameter 0,350 $\mathrm{mm}$ ) and M500 (diameter 0,580 $\mathrm{mm}$ ). The top of the curve for the smaller orifice is moved to a lower distance L/d between the sample and orifice. This confirms the hypothesis about the relation between Rayleigh time of a bubble collapse and the velocity of its motion. Detailed data contains [1].

\section{Conclusion}

The research of effects of cavitating jets showed, that the material disintegration by this way is possible. The results were obtained for materials without the stress hardening ability. The intensity of the material disintegration is dependent on a distance between orifice and surface. It was found that the cavitation damage has two base forms. The first one is concentrated to a smaller area and penetrating deeper inside the material. The second one is shallow and spread on a greater area.

The mass loss in dependence on the distance $\mathrm{L} / \mathrm{d}$ is presented for 2 micro-orifices of different sizes. The top of the mass loss curve is moved to lower distances for smaller orifice. This could be explained by the fact that smaller vapour bubbles have shorter Rayleigh time.

The results of experiments may be generalised for materials without stress hardening ability.

\section{References}

1. M. Mlkvik: Výskum viacfázových tokov v hydraulických kanáloch vel'mi malých rozmerov, Thesis - SjF STU v Bratislave, 2012

2. D. A. Summers, P. N. Worsey, The Use Of High Pressure Water Jets To Wash Out Explosives, Proc. 6th Int. Conf. On Erosion By Liquid And Solid Impact, 1999

3. S. Hattori, E. Nakao, Evaluation Of Cavitation Erosion Based On Erosion Particles, Third International Symposium On Cavitation (Cav 2001), 2001

\section{Acknowledgement}

This work was supported by the Scientific Grant Agency VEGA under contract number 1/0215/11. 